\title{
Concomitant familial hypocalciuric hypercalcemia and single parathyroid adenoma: a case report
}

Simone Diedrichsen Marstrand ${ }^{1}$, Charlotte Landbo Tofteng², Anne Jarløv' ${ }^{1}$ Line Borgwardt ${ }^{3}$ and

Peter Schwarz ${ }^{1,45^{*}}$ (1)

\begin{abstract}
Background: Primary hyperparathyroidism (PHPT) is a common endocrine disorder and the most frequent benign cause of hypercalcemia. PHPT is characterized by autonomous hypersecretion of parathyroid hormone (PTH), regardless of serum calcium levels. Familial hypocalciuric hypercalcemia $(\mathrm{FHH})$ is a rare, benign syndrome only affecting the regulation of calcium metabolism. FHH is an autosomal-dominant genetic disease with high penetrance, caused by an inactivating variant in the CASR gene encoding the calcium-sensing receptor (CaSR). We present a unique case of concomitant PHPT and FHH without clinically actionable variants in MEN1.
\end{abstract}

Case presentation: A 47-year-old Caucasian man with severe hypercalcemia, genetic $\mathrm{FHH}$, and initially normal parathyroid scintigraphy was referred for endocrine evaluation due to nonspecific symptoms. Biochemical evaluation showed elevated serum ionized calcium and PTH. The calcium-creatinine clearance ratio was low. All other biochemical measures were normal, including kidney function. Genetic evaluation was redone and confirmed FHH. A new parathyroid scintigraphy showed a significant single adenoma corresponding to the lower left gland. The patient underwent parathyroidectomy, and a parathyroid adenoma was removed. A reduced level of hypercalcemia persisted due to $\mathrm{FHH}$.

Conclusions: The correct diagnosis of the underlying cause of hypercalcemia is important to ensure the right treatment. Patients with FHH should avoid operative treatment, and PHPT should be differentiated from MEN1 to determine whether surgery should include parathyroidectomy with removal of one adenoma or 3.5 hyperplastic parathyroid glands.

Keywords: Primary hyperparathyroidism, FHH, MEN1

\section{Background}

Primary hyperparathyroidism (PHPT) is a common endocrine disorder and is the most frequent benign cause of hypercalcemia. It is characterized by autonomous hypersecretion of parathyroid hormone (PTH), independently of serum calcium levels. Parathyroid adenoma(s)

*Correspondence: peter.schwarz@regionh.dk

${ }^{5}$ Department of Endocrinology, Rigshospitalet, Blegdamsvej 9, 2100 Copenhagen, Denmark

Full list of author information is available at the end of the article and parathyroid hyperplasia are the main causes of PHPT [1]. Familiar forms of PHPT (FPHPT) represent less than $5 \%$ of the total PHPT cases and include, among others, familial hypocalciuric hypercalcemia $(\mathrm{FHH})$ and multiple endocrine neoplasia types 1 and 2A (MEN1 and MEN2A) [2].

FHH is a rare, benign syndrome only affecting the regulation of calcium metabolism, as first reported in 1972 by Foley et al. [3]. The familiar form FHH is an autosomaldominant genetic disease with high penetrance, caused by an inactivating variant in the CASR gene encoding original author(s) and the source, provide a link to the Creative Commons licence, and indicate if changes were made. The images or other third party material in this article are included in the article's Creative Commons licence, unless indicated otherwise in a credit line to the material. If material is not included in the article's Creative Commons licence and your intended use is not permitted by statutory regulation or exceeds the permitted use, you will need to obtain permission directly from the copyright holder. To view a copy of this licence, visit http://creativecommons.org/licenses/by/4.0/. The Creative Commons Public Domain Dedication waiver (http://creativeco mmons.org/publicdomain/zero/1.0/) applies to the data made available in this article, unless otherwise stated in a credit line to the data. 


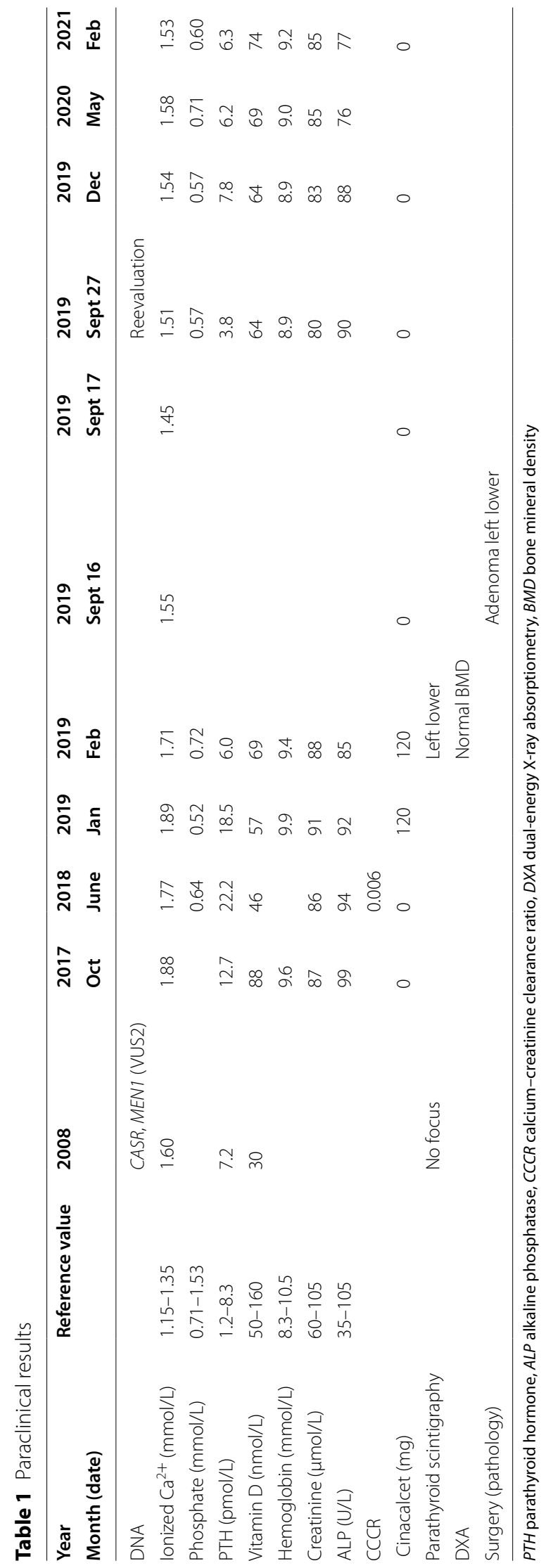


the calcium-sensing receptor (CaSR), first reported by Pollack et al. in 1993 [4]. Since then, other pathogenic variants in GNA11 and AP2S1 have been introduced in clinical practice. The pathogenic variants lead to lifelong hypercalcemia, with no other organ involvement. Other FPHPTs are frequently associated with other endocrine, proliferative, and/or functional disorders, such as non-endocrine tumors associated with MEN1, MEN2A, MEN4, and hereditary hyperparathyroidism-jaw tumor syndrome (HPT-JT) [5].

A small number of cases have reported parathyroid adenoma in patients with FHH [6-13]. In this case report we present a 47-year-old man with severe hypercalcemia, genetic $\mathrm{FHH}$, and a significant parathyroid adenoma at the lower left gland, without clinically actionable variants in MEN1.

\section{Case presentation}

In May 2017 the Caucasian patient was admitted to an endocrine clinic due to 6 months of nonspecific symptoms. The patient suffered from general malaise, nonspecific abdominal pain, and paresthesia in his fingers. He had a known history of FHH type 1 which was genetically confirmed in 2008 , identifying the pathogenic (class 5) heterozygous CASR variant (NM_000388, c.644A>G, p.Asp215Gly in exon 4). The patient owned a mediumsized service company. He lived in the countryside with his wife and children. He had never smoked. At first admission, the patient had no signs of kidney stones and received no treatment. Biochemical evaluation showed elevated plasma ionized calcium (iCa) of $1.87 \mathrm{mmol} / \mathrm{L}$ and PTH $17.0 \mathrm{pmol} / \mathrm{L}$ with low 25-hydroxy vitamin D (25OHD) of $21 \mathrm{nmol} / \mathrm{L}$ and phosphate $0.60 \mathrm{mmol} / \mathrm{L}$. The kidney function was normal, and the initial parathyroid scintigraphy revealed no focus (Table 1). The results of clinical evaluation were normal, with height of $182 \mathrm{~cm}$, weight $83 \mathrm{~kg}$, blood pressure 130/82, heart rate 48 beats per minute, and normal electrocardiography (ECG.) No signs of musculoskeletal symptoms and no neurological symptoms were observed.

After 5 months of treatment with $50 \mu \mathrm{g}$ vitamin D daily, 25OHD had normalized to $88 \mathrm{nmol} / \mathrm{L}$ and $\mathrm{PTH}$ had decreased to $12.5 \mathrm{pmol} / \mathrm{L}$. However, the symptoms of tiredness, abdominal pain, and hypercalcemia of $\mathrm{iCa} 1.88$ $\mathrm{mmol} / \mathrm{L}$ remained unchanged. An abdominal computed tomography $(\mathrm{CT})$ scan showed chronic pancreatitis but no renal calcification. The patient was observed (watchful waiting) until June 2018, with no change in clinical symptoms during this period.

In June 2018, reevaluation of the patient showed iCa $1.77 \mathrm{mmol} / \mathrm{L}$, PTH $22.2 \mathrm{pmol} / \mathrm{L}$ with $25 \mathrm{OHD}$ of 46 $\mathrm{nmol} / \mathrm{L}$, and phosphate $0.64 \mathrm{mmol} / \mathrm{L}$. The calciumcreatinine clearance ratio was low, 0.006. All other biochemical measures were normal, including the kidney function.

Three months later, cinacalcet treatment of $60 \mathrm{mg}$ per day was initiated due to persisting high iCa and PTH levels. However, the iCa and PTH levels did not change, and cinacalcet was terminated. In January 2019, cinacalcet was reintroduced due to persistent high levels of $\mathrm{iCa}$ of $1.89 \mathrm{mmol} / \mathrm{L}$ and PTH of $18.5 \mathrm{pmol} / \mathrm{L}$. A new parathyroid scintigraphy (subtractions-single-photon emission computed tomography/CT) revealed a single adenoma equivalent to the lower left gland corresponding to finding a 1.5-cm adenoma on CT evaluation (Fig. 1).

After a month, the cinacalcet dosage was increased to $60 \mathrm{mg}$ twice daily, as the initial dosage of $60 \mathrm{mg}$ once daily only resulted in a decrease in $\mathrm{iCa}$ to $1.71 \mathrm{mmol} / \mathrm{L}$. A dual-energy X-ray absorptiometry (DXA) scan confirmed normal bone mineral density.

After the diagnosis of PHPT was confirmed, parathyroid surgery was completed in September 2019. A single 0.828-g parathyroid adenoma was removed in toto from beneath the left thyroid lobe. PTH decreased $52 \%$ perioperatively. The day after surgery, iCa was $1.45 \mathrm{mmol} / \mathrm{L}$. Two weeks post-surgery, iCa was $1.51 \mathrm{mmol} / \mathrm{L}$, and PTH normalized at $3.8 \mathrm{pmol} / \mathrm{L}$. Since surgery, the patient has had no symptoms apart from his chronic pancreatitis. Clinically, the patient showed no hypercalcemic symptoms: blood pressure $121 / 69$, heart rate 50 beats per minute. Respiratory findings were normal, with a rate of 12 breaths per minute and $99 \%$ saturation.

Genetic evaluation was redone, adding sequencing of other genes associated with hyperparathyroidism (AP2S1, CASR, CDC73, CDKN1B, GNA11, MEN1 and $R E T)$ including screening for mosaicism. Apart from a likely benign (class 2) MEN1 variant (c.762 G>A, p.Leu254Leu), no clinically actionable variants were added. The patient was clinically reevaluated 12 month postoperatively with no sign of hypercalcemic symptoms: weight stable at $83.9 \mathrm{~kg}$; height $182 \mathrm{~cm}$; BMI 24.7 . Blood pressure was normal at 130/82. ECG was clinically normal with a heart rate of 48 beats per minute; no respiratory pathological findings; no sign of musculoskeletal symptoms; and no neurological symptoms.

In order to confirm that the remaining hypercalcemia was due to $\mathrm{FHH}$, we found that his cousin carried the same CASR, c.644A>G, p.Asp215Gly (Fig. 2), and had iCa of $1.44 \mathrm{mmol} / \mathrm{L}$ and $\mathrm{PTH}$ of $2.1 \mathrm{pmol} / \mathrm{L}$ without any other symptoms of disease. The elevated iCa and corresponding normal PTH of this family member confirmed the pathogenicity of the CASR variant leading to elevated iCa without hyperparathyroidism. 


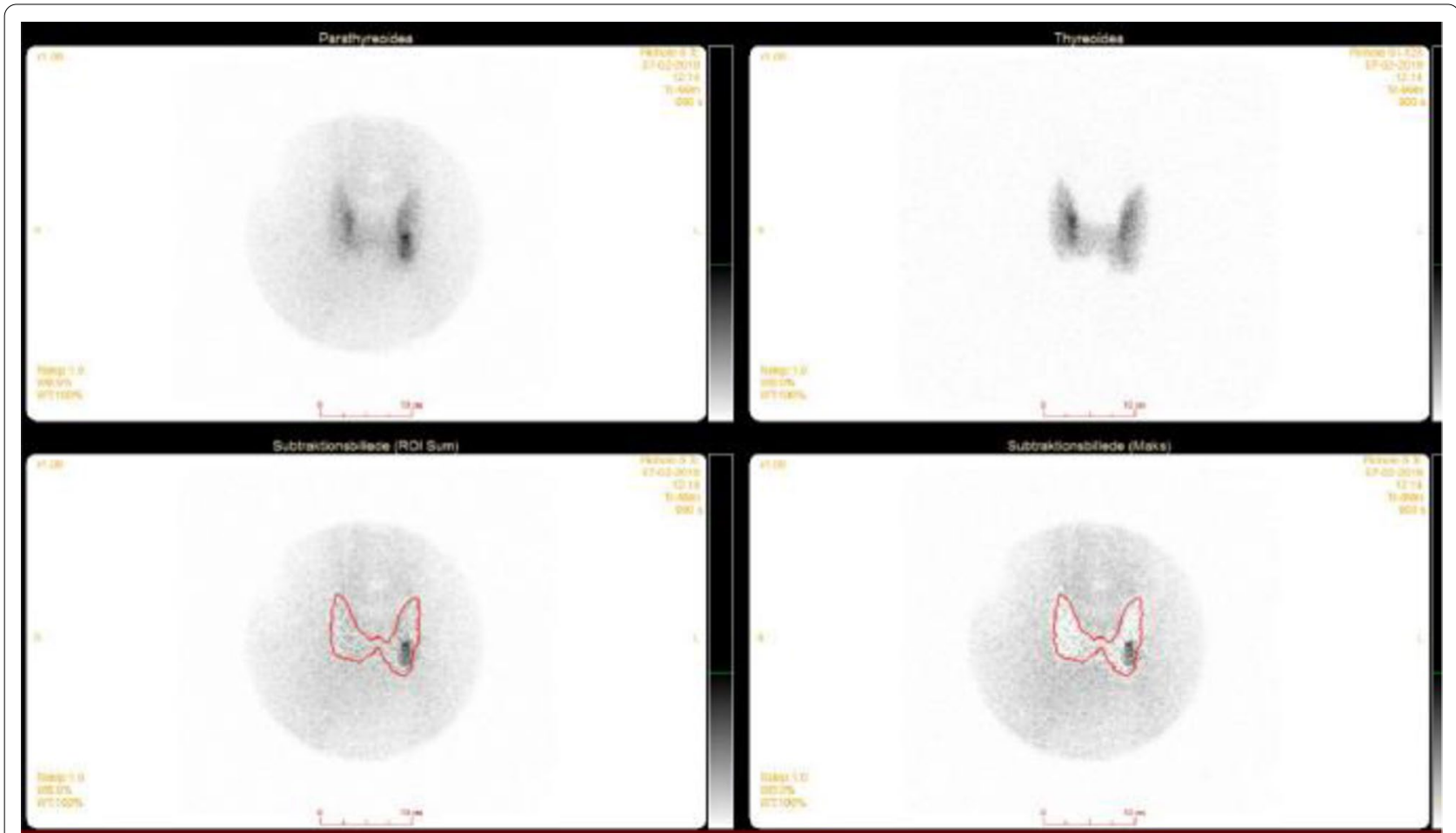

Fig. 1 Parathyroid scintigraphy from February 2019 showing a single adenoma at the lower left gland

\section{Discussion and conclusions}

The present case is an example of severe hypercalcemia in a middle-aged man with known FHH due to the development of a parathyroid adenoma. Treatment with high-dose cinacalcet was necessary to lower $\mathrm{iCa}$ and improve the patient's well-being during the diagnostic period. Parathyroidectomy normalized PTH levels and reduced hypercalcemia, and the patient's hypercalcemic symptoms resolved. PHPT is a common disease in adults. The high parathyroid state in PHPT causes increased renal absorption of calcium, increased bone turnover, and increased activated vitamin $\mathrm{D}$, which in turn enhances calcium absorption from the intestine. PHPT is often asymptomatic and randomly discovered, and only in rare cases can lead to severe life-threatening hypercalcemia. In contrast to PHPT, FHH is a rare, genetic disorder which predominantly results in asymptomatic hypercalcemia with no significant clinical consequences. Our patient had a known pathogenic (class 5) heterozygous CASR variant (NM_000388, c.644A>G, p.Asp215Gly in exon 4). The variant had previously been identified in another family with $\mathrm{FHH}$, and a functional study had confirmed that the variant leads to inactivation of the protein [14, 15]. The two diseases may share clinical manifestations and biochemical findings as presented in this and other cases. Previous cases of simultaneously diagnosed
PHPT and FHH in patients presenting with hypercalcemic symptoms have been described $[6-9,11,12]$. Distinguishing between the two entities can be complicated and must be carefully taken into consideration in the evaluation of hypercalcemia [16]. Reevaluation is necessary if the patient presents residual hypercalcemia after parathyroidectomy. In this case, as in a few others, PHPT develops in a patient with known $\mathrm{FHH}$, which may lead to diagnostic delay, as the clinicians may be more likely to attribute the hypercalcemia to the known disease [10, 13]. Later presentation of hypercalcemic symptoms or organ manifestations, as in our patient developing general malaise and chronic pancreatitis with no obvious cause, should lead to diagnostic reevaluation. Pancreatitis secondary to both PHPT and FHH has been described $[17,18]$. The mechanisms, however, are not fully understood. Our patient had persistent nonspecific abdominal symptoms even after parathyroid surgery had restored the calcium levels to $\mathrm{FHH}$ baseline levels, probably due to his chronic pancreatitis. These examples of coexisting hypercalcemic disease highlight the importance of following standard diagnostic measures for hypercalcemia as recommended in international guidelines, and reevaluating the patient if changes in clinical or biochemical presentation occur $[2,19]$. The consensus of a standard biochemical measure to differentiate between $\mathrm{FHH}$ and PHPT is the 


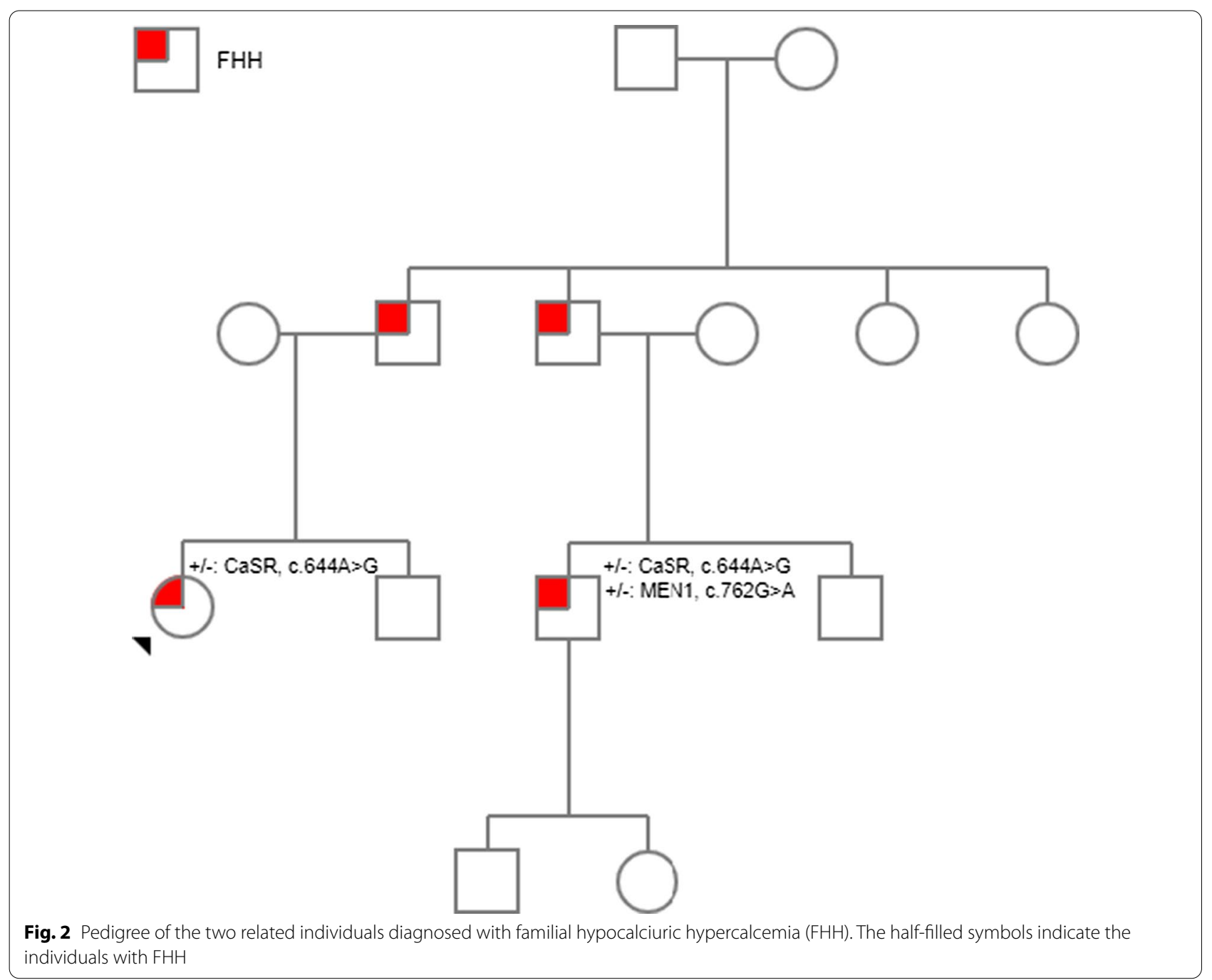

calcium-creatinine clearance ratio. This measure is not useful for diagnosing concomitant FHH and PHPT, as in the present case. In addition, a recent study showed limitations of the calcium-creatinine clearance ratio in general in differentiating between $\mathrm{FHH}$ and PHPT [20]. Thus, a combination of clinical symptoms, family history, biochemical testing, parathyroid scintigraphy, and genetic testing is required to distinguish $\mathrm{FHH}$ from PHPT and also to exclude MEN1. In our case, there was a known variant of unknown significance in MEN1 at the first genetic analysis. As the patient developed PHPT years later, the MEN1 variant was reevaluated and classified as likely benign. The variant was classified in accordance with American College of Medical Genetics and Genomics (ACMG) guidelines [21]. In conclusion, correct diagnosis of the underlying cause of hypercalcemia is important to ensure the right treatment, as highlighted by the present case of a patient with known FHH developing PHPT. Patients with FHH should avoid operative treatment, and PHPT should be differentiated from MEN1 to determine whether parathyroidectomy should include the removal of one adenoma or 3.5 hyperplastic parathyroid glands.

\section{Patient perspective}

The patient was afraid of malignant parathyroid disease and treatment thereof as he since childhood had been aware of the FHH diagnosis and reassured of the benign genesis.

\section{Acknowledgements}

Not applicable.

\section{Authors' contributions}

SDM analyzed and interpreted the patient data and drafted the manuscript. LB performed genetic analysis and discussed and revised the manuscript. PS, $\mathrm{AJ}$, and CLT performed the medical examinations and initiated diagnostic tests and treatment, discussed findings, and revised the manuscript. All authors read and approved the final manuscript. 


\section{Funding}

Not applicable

\section{Availability of data and materials}

All relevant patient data are included in the case report, and further supporting data may be obtained on request.

\section{Declarations}

Ethics approval and consent to participate Not applicable.

\section{Consent for publication}

Written informed consent was obtained from the patient for publication of this case report and any accompanying images. A copy of the written consent is available for review by the Editor-in-Chief of this journal.

\section{Competing interests}

The authors declare that they have no competing interests.

\section{Author details}

'Department of Endocrinology \& Diabetes and Bone-metabolic Research Unit, Rigshospitalet, Copenhagen, Denmark. ${ }^{2}$ Department of Medicine, Zealand University Hospital, Køge, Denmark. ${ }^{3}$ Center for Genomic Medicine, Copenhagen University Hospital, Rigshospitalet, Copenhagen, Denmark. ${ }^{4}$ Faculty of Health Sciences, University of Copenhagen, Copenhagen, Denmark. ${ }^{5}$ Department of Endocrinology, Rigshospitalet, Blegdamsvej 9, 2100 Copenhagen, Denmark.

Received: 17 April 2020 Accepted: 6 August 2021

Published online: 24 September 2021

\section{References}

1. Bilezikian JP, Bandeira L, Khan A, Cusano NE. Hyperparathyroidism. Lancet. 2018;391(10116):168-78.

2. Bilezikian JP, Cusano NE, Khan AA, Liu JM, Marcocci C, Bandeira F. Primary hyperparathyroidism. Nat Rev Dis Primers. 2016;2:16033.

3. Foley TP Jr, Harrison HC, Arnaud CD, Harrison HE. Familial benign hypercalcemia. J Pediatr. 1972;81 (6):1060-7.

4. Pollak MR, Brown EM, Chou YH, Hebert SC, Marx SJ, Steinmann B, et al. Mutations in the human $\mathrm{Ca}(2+)$-sensing receptor gene cause familial hypocalciuric hypercalcemia and neonatal severe hyperparathyroidism. Cell. 1993;75(7):1297-303.

5. Cristina EV, Alberto F. Management of familial hyperparathyroidism syndromes: MEN1, MEN2, MEN4, HPT-Jaw tumour, Familial isolated hyperparathyroidism, $\mathrm{FHH}$, and neonatal severe hyperparathyroidism. Best Pract Res Clin Endocrinol Metab. 2018;32(6):861-75.

6. Forde HE, Hill AD, Smith D. Parathyroid adenoma in a patient with familial hypocalciuric hypercalcaemia. BMJ Case Rep. 2014;2014:1.

7. Burski K, Torjussen B, Paulsen AQ, Boman H, Bollerslev J. Parathyroid adenoma in a subject with familial hypocalciuric hypercalcemia: coincidence or causality? J Clin Endocrinol Metab. 2002;87(3):1015-6.

8. Brachet C, Boros E, Tenoutasse S, Lissens W, Andry G, Martin P, et al. Association of parathyroid adenoma and familial hypocalciuric hypercalcaemia in a teenager. Eur J Endocrinol. 2009:161(1):207-10.
9. Yabuta T, Miyauchi A, Inoue H, Yoshida H, Hirokawa M, Amino N. A patient with primary hyperparathyroidism associated with familial hypocalciuric hypercalcemia induced by a novel germline CaSR gene mutation. Asian J Surg. 2009;32(2):118-22.

10. Egan AM, Ryan J, Aziz MA, O'Dwyer TP, Byrne MM. Primary hyperparathyroidism in a patient with familial hypocalciuric hypercalcaemia due to a novel mutation in the calcium-sensing receptor gene. J Bone Miner Metab. 2013;31(4):477-80.

11. Papadakis M, Meurer N, Margariti T, Meyer A, Weyerbrock N, Dotzenrath C. A novel mutation of the calcium-sensing receptor gene in a German subject with familial hypocalciuric hypercalcemia and primary hyperparathyroidism. Hormones (Athens). 2016;15(4):557-9.

12. Sagi SV, Joshi H, Trotman J, Elsey T, Swamy A, Rajkanna J, et al. A novel CASR variant in a family with familial hypocalciuric hypercalcaemia and primary hyperparathyroidism. Endocrinol Diab Metab Case Rep. 2020;2020:1.

13. Kay S, Piltin M, Loseva V, Sinnott B, Brennan JR, Mehrotra S, et al. Collision diagnoses: primary hyperparathyroidism layered on familial hypocalciuric hypercalcemia. AACE Clinical Case Reports. 2018;4(5):e362-6.

14. Heath H 3rd, Odelberg S, Jackson CE, Teh BT, Hayward N, Larsson C, et al. Clustered inactivating mutations and benign polymorphisms of the calcium receptor gene in familial benign hypocalciuric hypercalcemia suggest receptor functional domains. J Clin Endocrinol Metab. 1996;81(4):1312-7.

15. White E, McKenna J, Cavanaugh A, Breitwieser GE. Pharmacochaperonemediated rescue of calcium-sensing receptor loss-of-function mutants. Mol Endocrinol. 2009;23(7):1115-23.

16. Shinall MC Jr, Dahir KM, Broome JT. Differentiating familial hypocalciuric hypercalcemia from primary hyperparathyroidism. Endocr Pract. 2013;19(4):697-702

17. Thareja S, Manrai M, Shukla R, Kumar Sood A, Jha A, Tyagi AK, et al. Pancreatitis and hyperparathyroidism: still a rare association! Med J Armed Forces India. 2019;75(4):444-9.

18. Bai HX, Giefer M, Patel M, Orabi Al, Husain SZ. The association of primary hyperparathyroidism with pancreatitis. J Clin Gastroenterol. 2012;46(8):656-61.

19. Bilezikian JP, Brandi ML, Eastell R, Silverberg SJ, Udelsman R, Marcocci C, et al. Guidelines for the management of asymptomatic primary hyperparathyroidism: summary statement from the Fourth International Workshop. J Clin Endocrinol Metab. 2014;99(10):3561-9.

20. Moore EC, Berber E, Jin J, Krishnamurthy V, Shin J, Siperstein A. Calcium creatinine clearance ratio is not helpful in differentiating primary hyperparathyroidism from familial herpercalcemic hypocalciuria: a study of 1000 patients. Endocr Pract. 2018;24:988-94.

21. Richards S, Aziz N, Bale S, Bick D, Das S, Gastier-Foster J, et al. Standards and guidelines for the interpretation of sequence variants: a joint consensus recommendation of the American College of Medical Genetics and Genomics and the Association for Molecular Pathology. Genet Med. 2015;17(5):405-24.

\section{Publisher's Note}

Springer Nature remains neutral with regard to jurisdictional claims in published maps and institutional affiliations.

Ready to submit your research? Choose BMC and benefit from

- fast, convenient online submission

- thorough peer review by experienced researchers in your field

- rapid publication on acceptance

- support for research data, including large and complex data types

- gold Open Access which fosters wider collaboration and increased citations

- maximum visibility for your research: over 100M website views per year

At BMC, research is always in progress.

Learn more biomedcentral.com/submissions 